\title{
3 in 1 Personal Health Record (PHR): Dalam Mendukung Gerakan Masyarakat Hidup Sehat (GERMAS)
}

\author{
3 in 1 Personal Health Record (PHR): \\ In Supporting The Gerakan Masyarakat Hidup Sehat (GERMAS)
}

\author{
Irmawati $^{1}$ \\ Adhani Windari ${ }^{2}$ \\ Marsum $^{3}$
1,2,3 Jurusan Rekam Medis dan Informasi Kesehatan Poltekkes Kemenkes Semarang
Jl. Tirto Agung, Pedalangan, Banyumanik, Semarang \\ E-mail: rmik@poltekkes-smg.ac.id
}

\begin{abstract}
The proportion of non-contagious diseases has increased in the last two years. The government has made efforts to accelerate and synergize promotional and preventive actions for healthy living in order to increase productivity and reduce health care costs through Inpres No.1 Tahun 2017 by launching the Gerakan Masyarakat Hidup Sehat (GERMAS). In previous research, a Personal Health Record (PHR) application was built as an effort to empower the community to support GERMAS. However, in this application there are still many limitedness.

The purpose of this research is to develop PHR application that are easier in accessibility, easier to use and more informative. The type of research that we used is descriptive quantitative research with evaluation and development approaches that describe the results of the identification, evaluation and development processes at each stage in the PHR application. Evaluation is carried out to assess the quality of information before and after the development of the information system of PHR application.

The results of this study are the multiplatform PHR GERMAS-V2 application more available, easier, and more informative.
\end{abstract}

Keywords: Personal Health Record (PHR); Gerakan Masyarakat Hidup Sehat (GERMAS)

\begin{abstract}
Abstrak
Proporsi penyakit tidak menular mengalami peningkatan dalam kurun waktu dua tahun terakhir. Pemerintah telah melakukan upaya dalam rangka mempercepat dan mensinergikan tindakan promotif dan preventif hidup sehat guna meningkatkan produktivitas dan menurunkan biaya pengobatan kesehatan melalui Inpres No.1 Tahun 2017 dengan mencanangkan Gerakan Masyarakat Hidup Sehat (GERMAS). Pada penelitian sebelumnya telah dibangun aplikasi Personal Health Record (PHR) sebagai upaya pemberdayaan masyarakat untuk mendukung GERMAS. Namun dalam aplikasi ini masih terdapat banyak keterbatasan.

Tujuan dari penelitian ini adalah untuk mengembangkan aplikasi yang lebih mudah dalam aksesibilitas, lebih mudah dalam penggunaan dan lebih informatif terkait data yang disajikan. Jenis penelitian yang digunakan adalah penelitian deskriptif kuantitatif dengan pendekatan evaluasi dan pengembangan yaitu mendeskripsikan hasil proses identifikasi, evaluasi dan pengembangan pada setiap tahapan dalam apilkasi PHR. Evaluasi dilakukan untuk menilai kualitas informasi yang dihasilkan sebelum dan sesudah pengembangan sistem informasi aplikasi PHR.

Hasil penelitian ini Aplikasi PHR GERMAS-V2 multiplatform lebih mudah digunakan oleh masyarakat luas (more available), mudah digunakan karena password dan username dapat ditentukan oleh pengguna sendiri (easier) dan data rekam hasil pemeriksaan kesehatan memberikan informasi terkait status kesehatan (more informative).
\end{abstract}

Kata kunci: Personal Health Record (PHR); Gerakan Masyarakat Hidup Sehat (GERMAS) 


\section{A.Pendahuluan}

Fenomena kesehatan yang terjadi saat ini di Indonesia adalah transisi epidemiologi (Irianto, 2014). Kondisi ini terjadi karena perubahan pola penyakit yang disebabkan pola gaya hidup modern (Heryana, 2016). Kondisi ini ditandai dengan meningkatnya kematian dan kesakitan akibat penyakit tidak menular (PTM) seperti stroke, hipertensi, penyakit jantung dan diabetes. Hal ini berdampak terhadap upaya peningkatan derajat kesehatan masyarakat. Proporsi PTM meningkat dalam dua tahun terakhir, tahun 2018 penyakit jantung $(44,04 \%)$, hipertensi $(22,13 \%)$ dan dibetes mellitus (14,69\%). Sedangkan tahun 2019 terjadi perubahan peringkat, hipertensi $(68,02 \%)$, diabetes mellitus $(16,04 \%)$ dan penyakit jantung sebanyak 26\%. (Dinkes Prov Jateng, 2019).

Pemerintah telah melakukan upaya mempercepat dan mensinergikan promotif dan preventif melalui Inpres No.1 Tahun 2017 dengan mencanangkan Gerakan Masyarakat Hidup Sehat (GERMAS). GERMAS merupakan tindakan yang sistematis dan terencana yang dilakukan bersama-sama oleh seluruh komponen bangsa dengan kesadaran, kemauan dan kemampuan berperilaku sehat guna meningkatkan kualitas hidup. Di tingkat provinsi, Provinsi Jawa Tengah melalui Pergub No. 35 Tahun 2017 mencanangkan GERMAS. Tujuan ditetapkannya pergub ini adalah untuk meningkatkan pemahaman, kesadaran, kemauan dan kemampuan masyarakat untuk berperilaku sehat dalam rangka meningkatkan kualitas hidup. Program Indonesia sehat dengan pendekatan GERMAS merupakan upaya pemerintah dalam membangun kemandirian masyarakat dalam hidup sehat sekaligus sebagai upaya promotif dan preventif yang pada akhirmya meningkatkan derajat kesehatan masyarakat. Namun upaya ini belum diimplementasikan secara optimal di masyarakat.
Pada penelitian sebelumnya telah dibangun aplikasi Personal Health Record (PHR) sebagai upaya pemberdayaan masyarakat untuk mendukung GERMAS. Dimana dalam aplikasi ini masing-masing individu dapat mencatat, memantau dan mengelola sendiri pola gaya hidupnya sehingga dapat meningkatkan kesadaran dirinya untuk hidup yang lebih sehat. Berdasarkan hasil evaluasi dari penggunaan aplikasi Personal Health Record (PHR) didapatkan data sebagai berikut: (Input) pengguna harus menggunakan password yang terdaftar, kondisi ini tidak memberikan keleluasaan pengguna melakukan pendaftaran sendiri atau Self-Registration. (Proses): Aplikasi berbasis web design, sangat membatasi pengguna dalam mengoperasionalkan aplikasi ini, harapannya lebih available dapat diunduh melalui playstore android. (Output): output belum informatif terkait dengan status kesehatan dan rekomendasi kesehatan, harapannya output lebih informatif. Berdasarkan hasil evaluasi perlu dilakukan pengembangan aplikasi PHR sebelumnya, yang meliputi tiga hal utama terkait dengan input, proses dan output dengan tujuan agar aplikasi friendlier, more informative dan healthier.

\section{B. Metode}

Penelitian deskriptif kuantitatif dengan pendekatan evaluasi dan pengembangan apilkasi PHR. Subyek penelitian petugas dinas kesehatan terkait, petugas puskesmas terkait dan masyarakat setempat. Sedangkan obyek penelitiannya Pengembangan aplikasi PHR.

Pengembangan aplikasi PHR sebagai variabel bebas dan adalah kualitas informasi sebagai variabel terikat dengan karakteristik meliputi ketersediaan informasi, aksesibilitas informasi, kesesuaian informasi dan kejelasan informasi.

Instrumen penelitian meliputi lembar fokus group diskusi, lembar ceklist dan kuesioner. Alur Penelitian meliputi studi pendahuluan (preliminary investigation), 
analisis masalah (problem analysis), analisis kebutuhan, analisis keputusan (decision analysis), tahap perancangan sistem (design system), tahap membangun sistem baru (construction) dan tahap penerapan system. Pada tahap penerapan sistem, dilakukan dengan cara melakukan uji coba terhadap sistem informasi yang baru dikembangkan.

Analisis Data dilakukan dengan analisis Isi (content analysis) dan analisis deskriptif untuk menilai kualitas informasi yang dihasilkan, dengan menghitung nilai rata-rata tertimbang sebelum dan setelah pengembangan sistem. Pengukuran dilakukan dengan menggunakan skala likert, yang terdiri dari 5 (lima) jawaban yaitu : sangat tidak setuju (STS), tidak setuju (TS), netral (N), setuju (S) dan sangat setuju (TS). Formula yang digunakan untuk menghitung rata-rata tertimbang adalah :

$$
\begin{aligned}
& \qquad \bar{X}=\frac{\sum \text { fi.wi }}{\sum \text { fi }} \\
& \bar{X}=\text { rata-rata tertimbang } \\
& \text { fi }=\text { frekuensi } \\
& \text { wi = bobot }
\end{aligned}
$$

Keterangan bobot jawaban check list pengukuran kualitas informasi:

$\begin{array}{ll}\text { Sangat Tidak Setuju (STS) } & =1 \\ \text { Tidak Setuju (TS) } & =2 \\ \text { Netral (N) } & =3 \\ \text { Setuju (S) } & =4 \\ \text { Sangat Setuju (SS) } & =5\end{array}$

\section{C.Hasil dan Pembahasan}

1. Aplikasi PHR GERMAS V-1 Sebelum Dilakukan Pengembangan

Aplikasi masih dirancang dalam bentuk satu platform (berbasis web) dan masih dirancang secara tertutup, belum bisa digunakan oleh masyarakat secara luas. URL: http://phr-germas.online/phr/. Pengguna harus mengisikan username dan password yang sudah didaftarkan agar dapat menggunakan aplikasi. Didalam proses memuat terkait data pribadi, aktivitas, perilaku sehat dan statistik. Data perilaku sehat mengacu kepada 9 (sembilan) kegiatan pokok yang meliputi aktifitas fisik, makan buah dan sayur, pemberian ASI, membersihkan lingkungan, pemeriksaan kesehatan, tidak merokok, tidak mengkonsumsi alkohol dan menggunakan jamban sehat. (Pergub No.35 Th 2017). Output dari penggunaan aplikasi ini masih bersifat monitoring atau merekapitulasi terkait pengisian data.

\section{Pengembangan Aplikasi PHR GERMAS-V2}

Pengembangan Aplikasi PHR GERMAS-V2 dimulai dengan analisis user requirement pembuatan aplikasi dan pembuatan Entity Relationship Diagram (ERD). Hasil analisis user requirement didapatkan data-data sebagai berikut: Jenis aplikasi web base dapat akses dimana saja dan kapan saja, user friendly, dan responsive web design user interface, support gadget display resolution. Pembuatan aplikasi meliputi beberapa tahapan, yaitu pembuatan diagram alir pengembangan system PHR, perancangan kontektual, dan membuat data flow diagram (DFD).

Berikut adalah gambaran pembuatan data flow diagram (DFD) pada pengembangan sistem PHR yang kedua

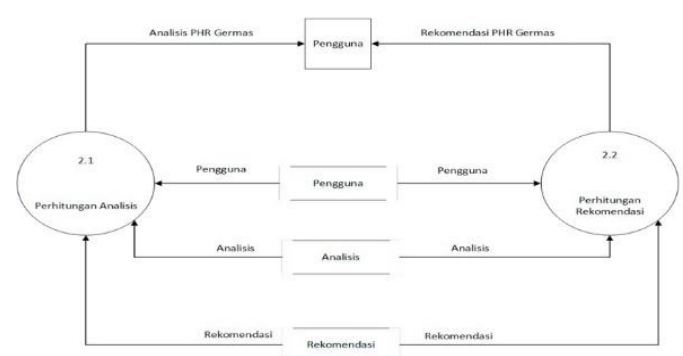

Gambar. DFD level 1 proses 2 PHR GERMAS V-2

Hasil pengembangan yang telah dilakukan pada aplikasi PHR GERMAS $\mathrm{V}-2$ dalam penelitian ini meliputi

a. More Available

Aplikasi PHR GERMAS-V2 ini dikembangkan dengan multiplatform selain dapat diakses dengan Web Browser, aplikasi ini juga dapat diakses menggunakan Perangkat Mobile (Android) yang dapat di unduh melalui Google Play Store, hal ini dilakukan agar Aplikasi PHR 
GERMAS-V2 semakin dekat dengan masyarakat. Tampilan yg dikembangkan sama persis dengan kedua platform tersebut agar masyarakat lebih mudah dalam mengaplikasikannya.

\section{b. Easier}

Dalam pengembangan aplikasi PHR GERMAS-V2 ini dikembangkan fitur baru yaitu pengguna dapat mendaftar sendiri secara gratis untuk menggunakan aplikasi PHR GERMAS-V2 ini, karena aplikasi ini hanya terbatas untuk beberapa orang saja, dikarenakan aplikasi dapat memberikan manfaat yg baik untuk masyarakat maka dari itu sistem ini dikembangkan untuk dapat digunakan masyarakat pada umumnya secara gratis.

c. More Informatife

Pada pengembangan aplikasi PHR GERMAS-V2 ini dilengkapi dengan informasi tentang monitoring dan rekomendasi terkait status kesehatan pribadi, status aktifitas dan status perilaku hidup sehatnya. Dengan adanya monitoring dan rekomendasi ini, kesehatan pribadi dapat dipantau secara mandiri dan dikontrol dengan lebih baik.

\section{Ujicoba Aplikasi PHR GERMAS Sesudah Pengembangan}

a. Uji Coba Aplikasi

Uji coba aplikasi yang digunakan adalah black box, yaitu menguji perangkat lunak dari segi spesifikasi fungsional tanpa menguji desain dan kode program. Pengujian dimaksudkan untuk mengetahui apakah fungsi-fungsi masukan dan keluaran dari perangkat lunak sesuai dengan spesifikasi yang dibutuhkan.

Tabel. Hasil Uji Black Box

\begin{tabular}{|c|c|c|c|}
\hline No & Skenario Pengujian & Hasil Yang Diharapkan & Kesimpulan \\
\hline 1 & $\begin{array}{l}\text { Mengisi username dan password user yang } \\
\text { tidak terdaftar, kemudian klik "Login" }\end{array}$ & $\begin{array}{l}\text { Sistem menolak karena harus } \\
\text { melakukan pendaftaran terlebih } \\
\text { dahulu, akan muncul pesan. } \\
\text { "Username Atau Password Salah / Akun } \\
\text { Belum Terdaftar, Silahkan Klik Daftar } \\
\text { Untuk Membuat Akun Baru" }\end{array}$ & Valid \\
\hline 2 & $\begin{array}{l}\text { Mengisi form pendaftaran akun untuk } \\
\text { pengguna baru, akan ditolak jika dimasukan } \\
e \text {-mail yang sama, setelah menekan tombol } \\
\text { "Daftar" }\end{array}$ & $\begin{array}{l}\text { Sistem akan menolak dan akan } \\
\text { muncul respon, "E-mail Sudah } \\
\text { Terdaftar, Masukan E-mail Lain." }\end{array}$ & Valid \\
\hline 3 & $\begin{array}{l}\text { Mengisi form pendaftaran akun untuk } \\
\text { pengguna baru, akan ditolak jika dimasukan } \\
\text { username yang sama, setelah menekan } \\
\text { tombol "Daftar" }\end{array}$ & $\begin{array}{l}\text { Sistem akan menolak dan akan } \\
\text { muncul respon, "Username Sudah } \\
\text { Terdaftar, Masukan Username Lain." }\end{array}$ & Valid \\
\hline 4 & $\begin{array}{l}\text { Mengisi form pendaftaran akun untuk } \\
\text { pengguna baru, akan ditolak jika dimasukan } \\
\text { password dan ulangi password tidak sama, } \\
\text { setelah menekan tombol "Daftar" }\end{array}$ & $\begin{array}{l}\text { Sistem akan menolak dan akan } \\
\text { muncul respon, "Password dan Ulangi } \\
\text { Password yang Anda masukan tidak } \\
\text { sama" }\end{array}$ & Valid \\
\hline 4 & $\begin{array}{l}\text { Mengisi pemeriksaan kesehatan sesuai } \\
\text { dengan kondisi pengguna, akan } \\
\text { memunculkan rekomendasi seperti pada } \\
\text { lampiran untuk point A sampai dengan point } \\
\text { E akan memunculkan status dan } \\
\text { rekomendasi dari masing - masing input } \\
\text { data. }\end{array}$ & $\begin{array}{l}\text { Menghasilkaan status dan } \\
\text { rekomendasi sesuai dengan lampiran } \\
\text { point A sampai dengan point E, sesuai } \\
\text { dengan input data yang dilakukan } \\
\text { oleh pengguna. }\end{array}$ & Valid \\
\hline 5 & $\begin{array}{l}\text { Pengisian salah satu aktifitas maupun } \\
\text { perilaku sehat akan muncul di data statustik } \\
\text { akumulasi dalam periode } 1 \text { bulan. }\end{array}$ & $\begin{array}{l}\text { Sistem akan menampilkan akumulasi } \\
\text { data pengisian aktifitas maupun } \\
\text { perilaku sehat dan } \\
\text { menampilkannya dalam } \\
\text { pengguna }\end{array}$ & Valid \\
\hline
\end{tabular}


Uji coba aplikasi dilakukan dengan menggunakan dua smartphone yaitu iPhoneXR dengan spesifikasi sebagai berikut resolusi 1792 × 828 piksel 326 ppi, iOS 13 dan menggunakan smartphone Samsung J7 Prime dengan spesifikasi sebagai berikut OS smartphone dan web V6.0 marshmallow, resolusi 1080×1921
(FHD). Pengujian dilakukan pada fungsi login, dashboard user, self-status dan self-statistic serta halaman bantuan, dari hasil uji coba fungsi pada kedua smartphone tersebut didapatkan hasil bahwa tampilan dan fungsi menu sesuai dengan yang diharapkan.

\section{b. Uji Coba Penggunaan Aplikasi}

Uji coba penggunaan aplikasi dilakukan pada 30 orang pengguna, dengan melakukan uji kualitas sistem dan uji kualitas informasi dilakukan dengan membagikan kuesioner.

Tabel. Distribusi Frekuensi Jawaban Responden Terhadap Uji Kualitas Sistem Sebelum pengembangan aplikasi PHR GERMAS

\begin{tabular}{|c|c|c|c|c|c|c|c|c|c|c|}
\hline & & & TS & & $S$ & & $\mathbf{N}$ & & S & SS \\
\hline No & Pernyataan & $\mathbf{F}$ & $\%$ & f & $\%$ & $f$ & $\%$ & f & $\%$ & $\%$ \\
\hline
\end{tabular}

\begin{tabular}{|c|c|c|c|c|c|c|c|c|c|c|c|}
\hline 1 & Aplikasi PHR mudah dioperasikan & 0 & 0 & 0 & 0 & 20 & 67 & 10 & 33 & 0 & 0 \\
\hline 2 & Input data mudah dilakukan & 0 & 0 & 10 & 33 & 10 & 33 & 10 & 33 & 0 & 0 \\
\hline 3 & Pencarian data mudah dilakukan & 0 & 0 & 20 & 67 & 10 & 33 & 0 & 0 & 0 & 0 \\
\hline 4 & $\begin{array}{l}\text { Sistem merekam data kesehatan secara } \\
\text { lengkap }\end{array}$ & 0 & 0 & 20 & 67 & 10 & 33 & 0 & 0 & 0 & 0 \\
\hline 5 & Menu yang tersedia sesuai kebutuhan & 0 & 0 & 10 & 33 & 20 & 67 & 0 & 0 & 0 & 0 \\
\hline 6 & $\begin{array}{l}\text { Sistem dapat menyimpan data dengan } \\
\text { benar }\end{array}$ & 0 & 0 & 0 & 0 & 20 & 67 & 10 & 33 & 0 & 0 \\
\hline 7 & $\begin{array}{l}\text { Sistem mampu menampilkan laporan } \\
\text { dengan tepat }\end{array}$ & 0 & 0 & 0 & 0 & 20 & 67 & 10 & 33 & 0 & 0 \\
\hline 8 & $\begin{array}{l}\text { Sistem dapat langsung menyimpan dan } \\
\text { memproses data }\end{array}$ & 0 & 0 & 0 & 0 & 20 & 67 & 10 & 33 & 0 & 0 \\
\hline & Jumlah & & & 60 & & 130 & & 50 & & 0 & \\
\hline
\end{tabular}

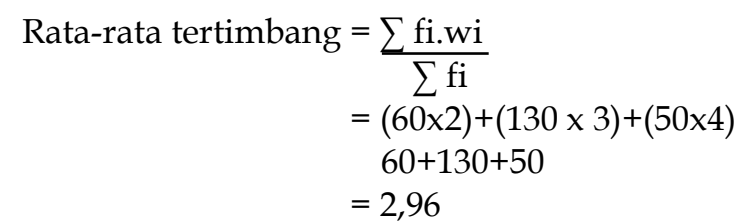


Tabel. Distribusi Frekuensi Jawaban Responden Terhadap Uji Kualitas Sistem pengembangan Aplikasi PHR GERMAS

\begin{tabular}{|c|c|c|c|c|c|c|c|c|c|c|c|}
\hline \multirow[b]{2}{*}{ No } & \multirow[b]{2}{*}{ Pernyataan } & \multicolumn{2}{|c|}{ STS } & \multicolumn{2}{|c|}{ TS } & \multicolumn{2}{|c|}{$\mathbf{N}$} & \multicolumn{2}{|c|}{$\mathbf{S}$} & \multicolumn{2}{|c|}{ SS } \\
\hline & & $\mathbf{f}$ & $\%$ & f & $\%$ & f & $\%$ & f & $\%$ & f & $\%$ \\
\hline 1 & Aplikasi PHR mudah dioperasikan & 0 & 0 & 0 & 0 & 0 & 0 & 28 & 93 & 2 & 7 \\
\hline 2 & Input data mudah dilakukan & 0 & 0 & 0 & 0 & 0 & 0 & 28 & 93 & 2 & 7 \\
\hline 3 & Pencarian data mudah dilakukan & 0 & 0 & 0 & 0 & 0 & 0 & 30 & 100 & 0 & 0 \\
\hline 4 & $\begin{array}{l}\text { Sistem merekam data kesehatan secara } \\
\text { lengkap }\end{array}$ & 0 & 0 & 0 & 0 & 5 & 17 & 25 & 83 & 0 & 0 \\
\hline 5 & Menu yang tersedia sesuai kebutuhan & 0 & 0 & 0 & 0 & 2 & 7 & 25 & 83 & 3 & 10 \\
\hline 6 & $\begin{array}{l}\text { Sistem dapat menyimpan data dengan } \\
\text { benar }\end{array}$ & 0 & 0 & 0 & 0 & 0 & 0 & 25 & 83 & 5 & 17 \\
\hline 7 & $\begin{array}{l}\text { Sistem mampu menampilkan laporan } \\
\text { dengan tepat }\end{array}$ & 0 & 0 & 0 & 0 & 0 & 0 & 28 & 93 & 2 & 7 \\
\hline 8 & $\begin{array}{l}\text { Sistem dapat langsung menyimpan dan } \\
\text { memproses data }\end{array}$ & 0 & 0 & 0 & 0 & 0 & 0 & 28 & 93 & 2 & 7 \\
\hline & Jumlah & & & & & 7 & & 217 & & 16 & \\
\hline & $\begin{aligned} \text { ta tertimbang } & =\frac{\sum \text { fi.wi }}{\sum \mathrm{fi}} \\
& =\frac{(7 \times 3)+(217 \times 4)+}{7+217+16} \\
& =4.04\end{aligned}$ & 16) & & & & & & & & & \\
\hline
\end{tabular}

Selisih rata-rata tertimbang $=4,04-2,96=1,08$

Berdasarkan tabel di atas diketahui bahwa 28 orang (93\%) setuju aplikasi PHR mudah dioperasikan, input mudah dilakukan, laporan ditampilkan dengan tepat dan system data menyimpan dan memproses data. Semua responden 10 orang $(100 \%)$ setuju bahwa pencarian data mudah dilakukan.
Sedangkan 25 responden (83\%) responden setuju bahwa menu yang tersedia sesuai kebutuhan dan mampu menyimpan data dengan benar. Tidak Ada responden yang menjawab pertanyaan dengan jawaban tidak setuju maupun sangat tidak setuju. 
Tabel. Distribusi Frekuensi Jawaban Responden Terhadap Uji Kualitas Informasi Sebelum Pengembangan Aplikasi PHR

\begin{tabular}{|c|c|c|c|c|c|c|c|c|c|c|c|}
\hline \multirow[b]{2}{*}{ No } & \multirow[b]{2}{*}{ Pernyataan } & \multicolumn{2}{|c|}{ STS } & \multicolumn{2}{|c|}{ TS } & \multicolumn{2}{|c|}{$\mathbf{N}$} & \multicolumn{2}{|c|}{$S$} & \multicolumn{2}{|c|}{ SS } \\
\hline & & f & $\%$ & f & $\%$ & f & $\%$ & f & $\%$ & f & $\%$ \\
\hline 1 & Informasi pada aplikasi PHR lengkap & 0 & 0 & 10 & 33 & 20 & 67 & 0 & 0 & 0 & 0 \\
\hline 2 & $\begin{array}{l}\text { Aplikasi PHR menyediakan informasi } \\
\text { yang dibutuhkan }\end{array}$ & 0 & 0 & 10 & 33 & 10 & 33 & 10 & 33 & 0 & 0 \\
\hline 3 & $\begin{array}{l}\text { Aplikasi PHR menyediakan informasi } \\
\text { yang up to date }\end{array}$ & 0 & 0 & 10 & 33 & 20 & 67 & 0 & 0 & 0 & 0 \\
\hline 4 & $\begin{array}{l}\text { Aplikasi PHR menyediakan informasi } \\
\text { yang cukup }\end{array}$ & 0 & 0 & 10 & 33 & 20 & 67 & 0 & 0 & 0 & 0 \\
\hline 5 & $\begin{array}{l}\text { Informasi pada aplikasi PHR mudah } \\
\text { ditemukan }\end{array}$ & 0 & 0 & 10 & 33 & 20 & 67 & 0 & 0 & 0 & 0 \\
\hline 6 & $\begin{array}{l}\text { Informasi pada aplikasi PHR sesuai } \\
\text { kebutuhan }\end{array}$ & 0 & 0 & 10 & 33 & 20 & 67 & 0 & 0 & 0 & 0 \\
\hline 7 & $\begin{array}{l}\text { Aplikasi PHR menyediakan informasi } \\
\text { tepat }\end{array}$ & 0 & 0 & 10 & 33 & 20 & 67 & 0 & 0 & 0 & 0 \\
\hline 8 & $\begin{array}{l}\text { Informasi pada aplikasi PHR jelas dan } \\
\text { mudah dimengerti }\end{array}$ & 0 & 0 & 0 & 0 & 30 & 100 & 0 & 0 & 0 & 0 \\
\hline 9 & $\begin{array}{l}\text { Status kesehatan pribadi dapat dipantau } \\
\text { secara mandiri }\end{array}$ & 0 & 0 & 20 & 67 & 10 & 33 & 0 & 0 & 0 & 0 \\
\hline & Jumlah & & & 90 & & 170 & & 10 & & & \\
\hline & $\begin{aligned} \text { ta-rata tertimbang } & =\sum \text { fi.wi } \\
& =\frac{\sum \mathrm{fi}}{90+170+10} \\
& =2,70\end{aligned}$ & $10 x$ & & & & & & & & & \\
\hline
\end{tabular}


Tabel.5.10 Distribusi Frekuensi Jawaban Responden Terhadap Uji Kualitas Informasi Aplikasi PHR

\begin{tabular}{|c|c|c|c|c|c|c|c|c|c|c|c|c|}
\hline \multirow[b]{2}{*}{ No } & \multirow[b]{2}{*}{ Pernyataan } & \multicolumn{2}{|c|}{ STS } & \multicolumn{2}{|c|}{ TS } & \multicolumn{3}{|c|}{$\mathbf{N}$} & \multicolumn{2}{|c|}{$S$} & \multicolumn{2}{|c|}{ SS } \\
\hline & & $\mathbf{F}$ & $\%$ & $\mathrm{f}$ & $\%$ & $f$ & $\%$ & & $f$ & $\%$ & $\mathbf{f}$ & $\%$ \\
\hline 1 & $\begin{array}{l}\text { Informasi pada aplikasi PHR } \\
\text { lengkap }\end{array}$ & 0 & 0 & 0 & 0 & 0 & & 0 & 30 & 100 & 0 & 0 \\
\hline 2 & $\begin{array}{l}\text { Aplikasi PHR menyediakan } \\
\text { informasi yang dibutuhkan }\end{array}$ & 0 & 0 & 0 & 0 & 0 & & 7 & 30 & 100 & 0 & 0 \\
\hline 3 & $\begin{array}{l}\text { Aplikasi PHR menyediakan } \\
\text { informasi yang up to date }\end{array}$ & 0 & 0 & 0 & 0 & 0 & & 0 & 30 & 100 & 0 & 0 \\
\hline 4 & $\begin{array}{l}\text { Aplikasi PHR menyediakan } \\
\text { informasi yang cukup }\end{array}$ & 0 & 0 & 0 & 0 & 0 & 5 & 0 & 30 & 100 & 0 & 0 \\
\hline 5 & $\begin{array}{l}\text { Informasi pada aplikasi PHR } \\
\text { mudah ditemukan }\end{array}$ & 0 & 0 & 0 & 0 & 0 & & 0 & 28 & 93 & 2 & 7 \\
\hline 6 & $\begin{array}{l}\text { Informasi pada aplikasi PHR sesuai } \\
\text { kebutuhan }\end{array}$ & 0 & 0 & 0 & 0 & 0 & & 0 & 28 & 93 & 2 & 7 \\
\hline 7 & $\begin{array}{l}\text { Aplikasi PHR menyediakan } \\
\text { informasi tepat }\end{array}$ & 0 & 0 & 0 & 0 & 0 & & 0 & 30 & 100 & 0 & 0 \\
\hline 8 & $\begin{array}{l}\text { Informasi pada aplikasi PHR jelas } \\
\text { dan mudah dimengerti }\end{array}$ & 0 & 0 & 0 & 0 & c & J & 0 & 30 & 100 & 0 & 0 \\
\hline 9 & $\begin{array}{l}\text { Status kesehatan pribadi dapat } \\
\text { dipantau secara mandiri }\end{array}$ & 0 & 0 & 0 & 0 & c & J & 0 & 28 & 83 & 2 & 7 \\
\hline
\end{tabular}

Rata-rata tertimbang $=\sum$ fi.wi

$$
\begin{aligned}
& =\frac{\sum \mathrm{fi}}{904 \times 4)+(6 \times 5)} \\
& =4,02
\end{aligned}
$$

Selisih rata-rata tertimbang $=4,02-$ $2,70=1,32$

Berdasarkan tabel diatas diketahui semua responden setuju bahwa aplikasi PHR dapat memberikan informasi yang lengkap, up to date, informasi yang cukup, jelas dan mudah dimengerti. Sebanyak 28 (93\%) responden memberikan jawaban setuju dan $2(7 \%)$ menjawab sangat setuju bahwa sistem menyediakan informasi yang dibutuhkan, informasi mudah ditemukan, sesuai kebutuhan dan status kesehatan pribadi dapat dipantau secara mandiri. Tidak ada responden yang memberikan jawaban sangat tidak setuju, tidak setuju dan netral.
Tabel 5.11 Distribusi Frekuensi kepuasan pengguna Aplikasi PHR

\begin{tabular}{llcc}
\hline No & \multicolumn{1}{c}{ Kriteria } & \multicolumn{2}{c}{ Jumlah } \\
\cline { 3 - 4 } & & $\mathbf{f}$ & $\mathbf{\%}$ \\
$\mathbf{1}$ & Sangat Tidak Setuju & 0 & 0 \\
$\mathbf{2}$ & Tidak Setuju & 0 & 0 \\
$\mathbf{3}$ & Netral & 0 & 0 \\
$\mathbf{4}$ & Setuju & 28 & 93 \\
$\mathbf{5}$ & Sangat Setuju & 2 & 7 \\
\multicolumn{2}{l}{ Total } & 30 & 100 \\
\hline
\end{tabular}

\section{D.Simpulan dan Saran}

\section{Simpulan}

1. Aplikasi PHR GERMAS-V2 mutiplatform, lebih mudah digunakan oleh masyarakat luas (more available), mudah digunakan karena password dan username dapat ditentukan oleh pengguna sendiri (easier) dan data rekam hasil pemeriksaan kesehatan memberikan informasi terkait status kesehatan (more informative) 
2. Uji kualitas sistem sebelum dan sesudah pengembangan telah dilaksankan dengan hasil selisih rerata tertimbang 1,32 dan uji kepuasan pengguna terhadap aplikasi PHR GERMAS-V2 telah dilaksanakan dengan hasil $93 \%$ setuju dan merasa puas

\section{Saran}

1. Aplikasi masih perlu dikembangkan dengan penambahan self-reminder pada aplikasi terkait kegiatan gerakan masyarakat hidup sehat yang harus dilakukan individu

2. Aplikasi diuji cobakan pada kelompok terbatas untuk mendapatkan data sebagai data dasar kesehatan masyarakat untuk dapat dilakukan berbagai analisis kesehatan selanjutnya.

\section{E. Ucapan Terima Kasih}

Terima kasih disampaikan kepada seluruh pihak yang turut serta membantu terlaksananya penelitian ini.

\section{F. Daftar Pustaka}

Azwar, Saifuddin. 2010. Metode Penelitian. Yogyakarta: Pustaka Pelajar.

Ambar Teguh Sulistyani. 2004. Kemitraan dan Model-Model Pemberdayaan.Yogyakarta : Graha Ilmu.

Basuki, Awan. Konsep dan Implementasi Pemrograman Lavarel 5 +. Lokomedia. 2015.

Buku Pintar Posbindu. 2019. Dirjen Pencegahan dan Pengendalian Penyakit Tidak menular. Kemenkes RI.

Dinas Kesehatan Propinsi Jawa Tengah. 2018. Profil Dinas Kesehatan Propinsi JawaTengah Tahun 2018.

Dinas Kesehatan Propinsi Jawa Tengah. 2019. Profil Dinas Kesehatan Propinsi JawaTengah Tahun 2019.

Helmer et al. 2011. Empowering Patients Trough Personal Health Record: a Survey of Existing Third-Party Web
Based PHR Products. Electronic Journal of Health Informatics.

Heryana, Ade, 2016. Transisi Epidemiologi.Universitas Esa Unggul. Jakarta.

Intruksi Presiden RI nomor 1 tahun 2017 Tentang Gerakan Masyarakat Hidup Sehat.

Indrajani. Perancanagan Basis Data. Alex Media Komputindo, 2011.

Irianto, Koes, 2014. Epidemiologi Penyakit Menular dan Tidak Menular Panduan Klinis. AlfabetaCv. Bandung.

Keputusan Menteri Kesehatan RI No. 585/MENKES/SK/V/2007 Tentang Pedoman Pelaksanaan Promosi Kesehatan di Puskesmas.

Peraturan Gubernur RI nomor 35 tahun 2017 tentang Gerakan Masyarakat Hidup sehat di Propinsi Jawa Tengah.

Kumorotomo, Wahyudi. Sistem Informasi Manajemen

Dalam

Organisasi-Organisasi Publik. Gadjah Mada University Press, Yogyakarta, 2015.

Raharjo, Budi. Otodidak MySqL: Teknik Pembuatan \& Pengelolaan Database. Informatika, 2015.

Sutabri, Tata. Analisis Sistem Informasi. Penerbit ANDI, 2012.

Soetomo. (2006). Strategi-strategi Pembangunan Masyarakat. Yogyakarta: Pustaka Pelajar.

Suparjan \& Hempri Suyatno. (2003). Pengembangan Masyarakat dari pembangunan Sampai Pemberdayaan. Yogyakarta: Aditya Media.

Undang-Undang No. 36 Tahun 2009 tentang Kesehatan.

Whitten, Jeffery L, Bentley Conie. System Analysis \& Design Methods Second Edition. Irwin Home Wood, Boston, 2001. 